\title{
Exploring the Health Outcomes of Conditional Cash Transfer Program in Rural Philippines
}

\section{Ericson H. Peñalba ${ }^{1}$}

ABSTRACT: The Pantawid Pamilya Pilipino Program (4Ps), the first conditional cash transfer (CCT) program of the Philippine government, has become a popular approach aimed at improving the health and educational status of disadvantaged households. Its implementation is expected to advance the government's health agenda, particularly in terms of child mortality reduction and maternal health improvement. Despite the growing evidence on the positive health outcomes resulting from the implementation of $\mathrm{CCT}$ programs, evidence remains limited to the qualitative evaluation of health care service utilization among beneficiary households. In this regard, by employing key interviews and focus group discussion, this study aims to examine the impacts of 4Ps on health and nutrition as experienced and perceived by beneficiaries at a community-level implementation. After subjecting the interview transcripts to thematic network analysis, the results reveal six dominant themes: enhanced health practices, improved uptake of health care services, increased awareness on health issues, improved living conditions, responsive program implementation, and persisting implementation challenges. While it is evident that the positive impacts are reflective of the beneficiaries' strict compliance to meet the program conditionalities, there is still much to be done to ensure the sustainability of the program. The provision for adequate health care should then be supplemented with reinforced delivery of the program's learning component (family development session) and support mechanism to the implementers.

Keywords: Conditional Cash Transfer, Social Welfare, Health Outcomes, Thematic Network Analysis

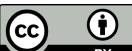

(C)2019 This work is licensed under the Creative Commons Attribution 4.0 International License. To view a copy of this license, visit http://creativecommons.org/licenses/by/4.0/.

\section{Introduction}

Conditional cash transfer (CCT) programs are interventions designed to improve the health condition and educational status of disadvantaged households. Initially implemented in Latin America in the mid-1990s, CCT programs have gradually become a popular approach to social

\footnotetext{
1 Social Science Researcher, Department of Teacher Education, Bulacan State University-Meneses campus, Bulacan, Philippines
} 
assistance and protection (Adato, \& Hoddinott, 2010). They are eventually introduced in other developing countries in South America and Asia. By 2008, at least 28 low- and middle-income countries had already implemented these programs; of these, 22 countries including the Philippines carry out health components (Fiszbein \& Schady, 2009).

As the foremost social welfare program of the Philippine government, the Pantawid Pamilyang Pilipino Program is targeted at the most underprivileged households with children aged 0 to 18 years. Similar to other CCT programs, it provides beneficiary households regular cash grants which are subject to specific requirements and conditions. Under the health component, each beneficiary receives Php500 per month or Php6,000 per year and has to comply with the uptake of the following health services: (1) regular pre- and post-natal checkup at the health center; (2) attendance in family development sessions (FDS); (3) regular preventive checkups, weighing, vaccination, and de-worming of children. Despite the progress made, the program has been criticized due to issues concerning the selection of target beneficiaries, size of cash transfer relative to poor household's income, and preparedness in providing essential social services (Reyes \& Tabuga, 2012). A specific problem is the inadequacy of health facilities in areas where the program is implemented (Fernandez \& Olfindo, 2011). Critics also argue that it is a dole-out initiative that only promotes a culture of mendicancy (Manasan, 2011).

The implementation of 4Ps is expected to help the national government achieve the key Millennium Development Goals by 2015 (Fernandez \& Olfindo, 2011). Central to the health agenda are the reduction of child mortality and improvement of maternal health. Although the Philippines is likely to achieve a significant reduction in child mortality, it is still far from lowering maternal mortality (National Economic and Development Council [NEDA], 2014). The number of maternal deaths steadily declined from 209 per 100,000 live births in 1990 to 162 per 100,000 live births in 2006; however, the ratio increased by 221 in 2011 (NEDA, 2014). In contrast, child mortality decreased from 12 per 1,000 live births to 2003 to 9 deaths per 1,000 in 2013 (Philippine Statistics Authority, 2014). In particular, according to a global index report by Save the Children Federation (2015), Metro Manila achieved a 40-per cent reduction in under-five deaths for the 1993-2013 period. The report also highlighted the contribution made by 4Ps in providing better access to health care services to achieve such progress. In support of this claim, a quantitative impact evaluation conducted by DSWD (2014) reported that the program has significantly improved children's access to basic health services like vitamin supplementation and immunization. 
The growing evidence on the positive health outcomes resulting from the implementation of CCT programs has mostly incorporated quantitative evaluations (Glassman et al., 2013; Adato, Roopnaraineb, \& Beckera, 2011). However, evidence remains limited particularly on a qualitative evaluation of health care service utilization among beneficiaries. For instance, Skovdal et al. (2013) employed focus group discussions and interviews to draw perceptions regarding a community-led cash transfer program. They reported that the program resulted in positive impacts on children's health and educational outcomes in Zimbabwe. Another qualitative study by OwusuAddo (2014) utilized semi-structured interviews to uncover dominant themes about how Ghana's CCT program substantially improves children's health. Also, Yildirim, Ozdemir, and Sezgin (2014) evaluated a CCT program in Turkey using in-depth interviews and found that it can foster improved health, educational and even psychological outcomes among children.

There is then a need to understand further how a CCT program like 4Ps can improve health outcomes among disadvantaged households. In this regard, drawing from the views and experiences of the beneficiaries is vital in further understanding the positive impacts of the program in terms of health care knowledge, decisions, and practices. It is also essential in surfacing implications on how the health care needs of beneficiaries can be better addressed through a responsive health service provision.

Considering the preceding statements, the general objective of this study is to examine the impacts of 4Ps on health outcomes, particularly on the health and nutrition practices of beneficiaries, at a community-level implementation. This research has the following specific objectives: (1) to determine the transformative aspects of the program in a rural setting in terms of engagement with health practices; utilization of health services, and knowledge on health issues; (2) to assess the current living conditions of the beneficiaries; (3) to evaluate the implementation and monitoring of the program at the community level; (4) to identify the existing problems encountered in the implementation and monitoring of the program; and (5) to analyze the implications of the study for the provision of health care services.

\section{Methods}

This qualitative study used a combination of key informant interview, focus group discussion (FGD), observation, and documentary analysis. The use of qualitative research design provided a more detailed and richer understanding of the insights and experiences of beneficiaries. In the context of evaluating CCT programs, specifically regarding the changes that occur in health and 
education indicators, qualitative methods are useful in providing "explanations for these changes, or lack of changes when they do not occur, and to understand program impacts that are harder to measure through a quantitative survey" (Maluccio, Adato, \& Skoufias, 2010, p. 42).

Data collection was carried out in the rural village of Malibong Matanda in the town of Pandi, province of Bulacan. The study site was one of the five villages in Pandi that served as the pilot area for the full implementation of the program in 2010. Prior to the collection of data, informed consent was secured from the participants. They were given a brief orientation about the purpose of the study and were also assured of confidentiality. Interviews were conducted with 20 purposively selected beneficiaries and five program implementers composed of two social workers, two community health workers, and one mother leader. An FGD was held to draw perspectives from selected participants composed of five beneficiaries, one parent leader, and two community health workers.

All of the beneficiaries were female household heads between 33 and 56 years old. Majority of them were housewives with the number of children ranging between 1 and 10 . Their spouses were mostly engaged in construction and agricultural occupations. To qualify as participants of the study, beneficiaries should have been receiving cash grants for at least three years and should have at least one child under the health component. Information obtained from observation and documentary analysis was used to supplement the interview responses.

An interview schedule consisting of open-ended questions was developed to gather insights from beneficiaries. A separate interview guide was created to explore the implementers' perspectives. The questions covered the following topics: responsibilities in meeting health conditionalities, use of cash grants, utilization of health care services, implementation and monitoring of the program, and perceived changes in living conditions.

All interviews were digitally recorded with the consent of the participants. The recordings were transcribed and subjected to a manual coding procedure. This process generated a total of 39 codes which were further subjected to thematic network analysis. As a systematic tool for analyzing qualitative data, thematic network analysis extracts and arranges themes from coded text segments to form a thematic network composed of basic, organizing, and global themes (Attride-Stirling, 2001). The coding framework utilized for this study employed the identification of recurrent themes or issues that were common across both key informant interviews and FGD. A summary of themes that emerged from a thorough analysis of the texts is presented in a table. 
Global Theme: Perceived Impacts of CCT program on health outcomes

\begin{tabular}{|c|c|c|}
\hline Codes & Basic themes & Organizing themes \\
\hline $\begin{array}{l}\text { Regular update of health record } \\
\text { Proper food selection } \\
\text { Monthly checkup at the health center } \\
\text { Purchase of vitamins }\end{array}$ & $\begin{array}{l}\text { Focus on health and } \\
\text { nutrition needs }\end{array}$ & Enhanced health practices \\
\hline $\begin{array}{l}\text { Vaccination } \\
\text { Pre-natal and post-natal checkup } \\
\text { De-worming } \\
\text { Immunization } \\
\text { Free medicines } \\
\text { Weight monitoring }\end{array}$ & $\begin{array}{l}\text { Access to health care } \\
\text { services }\end{array}$ & $\begin{array}{l}\text { Improved uptake of health } \\
\text { care services }\end{array}$ \\
\hline $\begin{array}{l}\text { Regular attendance at Family } \\
\text { Development Session } \\
\text { Additional knowledge through FDS } \\
\text { Knowledge in Family Planning } \\
\text { Knowledge about personal hygiene } \\
\text { practices }\end{array}$ & Health education & $\begin{array}{l}\text { Increased awareness of } \\
\text { health issues }\end{array}$ \\
\hline $\begin{array}{l}\text { Opportunity to improve children's } \\
\text { conditions } \\
\text { Budgeting of cash grant } \\
\text { Looking for other means to earn money }\end{array}$ & $\begin{array}{l}\text { Sense of initiative and } \\
\text { responsibility }\end{array}$ & Improved living conditions \\
\hline $\begin{array}{l}\text { Letting go of vices } \\
\text { Preparedness attitude } \\
\text { Children no longer sickly }\end{array}$ & Life transformations & \\
\hline $\begin{array}{l}\text { Coordination among implementers } \\
\text { High percentage of compliance }\end{array}$ & $\begin{array}{l}\text { Coordinated } \\
\text { implementation of the } \\
\text { program }\end{array}$ & $\begin{array}{l}\text { Responsive program } \\
\text { implementation }\end{array}$ \\
\hline $\begin{array}{l}\text { Usage of monitoring tools } \\
\text { Home visit } \\
\text { Regular monitoring through FDS } \\
\text { Visit to the health center } \\
\text { Awareness of being monitored among } \\
\text { beneficiaries } \\
\text { Awareness of the consequences due to } \\
\text { non-compliance among beneficiaries }\end{array}$ & $\begin{array}{l}\text { Efficient monitoring of } \\
\text { compliance to the program }\end{array}$ & \\
\hline $\begin{array}{l}\text { Complaints from beneficiaries } \\
\text { Pawning of cash card } \\
\text { Program as only a source of money } \\
\text { Lack of incentives for volunteers } \\
\text { Limited numbers of workers } \\
\text { Non-compliance of few beneficiaries } \\
\text { Delayed release of the cash grant } \\
\text { Deficient cash grant } \\
\text { Blame on health workers } \\
\text { Inability to attend FDS } \\
\text { Children not included in the master list }\end{array}$ & $\begin{array}{l}\text { Problems encountered by } \\
\text { implementers }\end{array}$ & $\begin{array}{l}\text { Persisting implementation } \\
\text { challenges }\end{array}$ \\
\hline
\end{tabular}




\section{Results}

Six organizing themes emerged relative to the observed impacts of 4Ps on health outcomes. As shown in the figure, the thematic network illustrates the basic and organizing themes on which the perceived impacts of the CCT Program on health outcomes was anchored. Specifically, the dominant organizing themes included the following: enhanced health practices, improved uptake of health care services, increased awareness on health issues, improved living conditions, responsive program implementation, and persisting implementation challenges. They are elaborated through a discussion of the basic themes derived from the text.

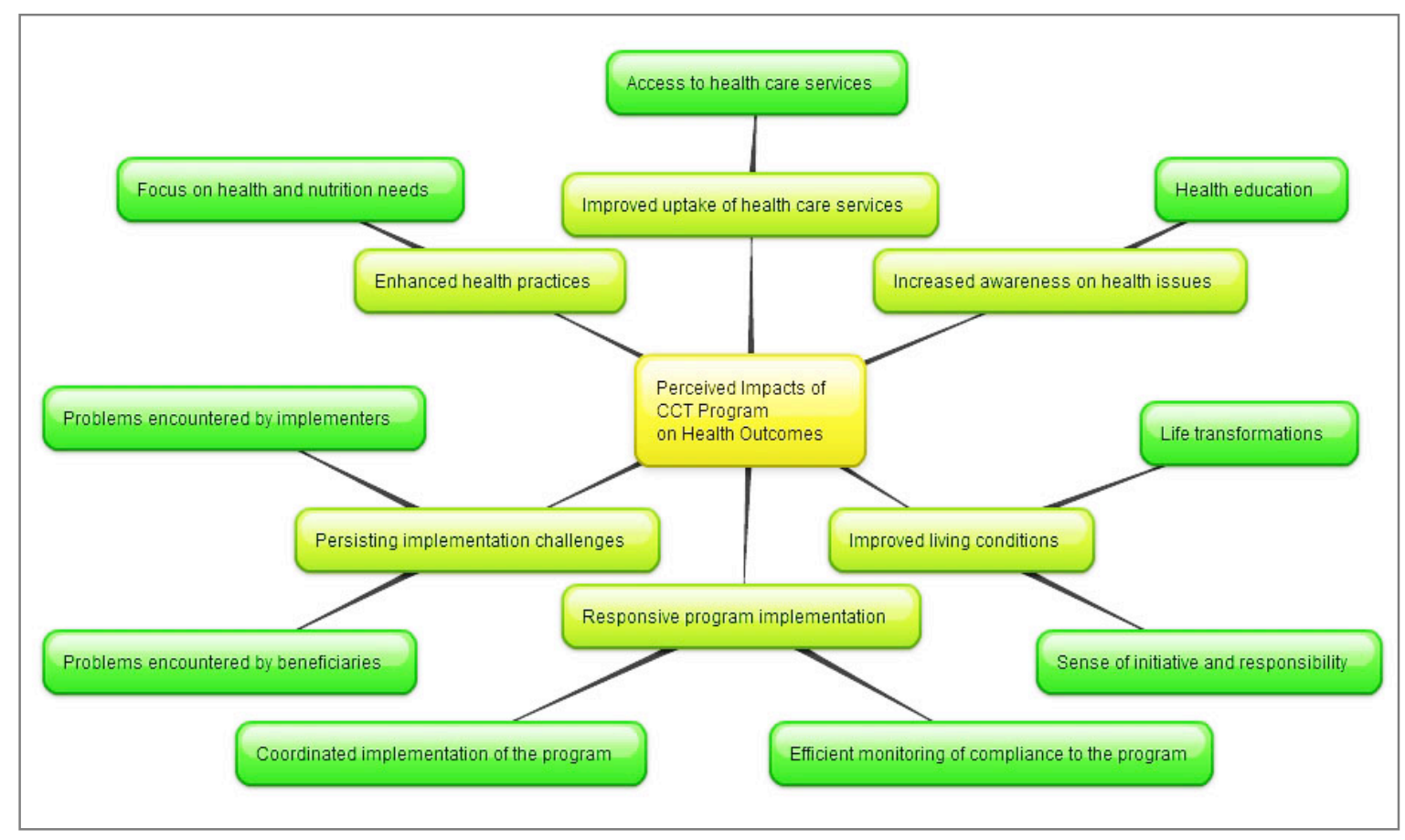

Thematic network of the Perceived Impacts of CCT Program on Health Outcomes

\subsection{Enhanced health and nutrition practices}

The 4Ps encouraged beneficiaries to prioritize their family's health needs. All participants recognized the relevance of not only exercising their responsibilities but also engaging in good health practices. In this regard, the receipt of cash grants was primarily associated with immediate response to children's needs. As a result, they habitually spent their cash grants for their children's health and nutritional needs. As one beneficiary said: "Right after receiving the cash grant, I buy my children's vitamins."

Notably, implementers observed how the program had transformed the beneficiaries' health practices. This was particularly evident on how cash grants were also spent on other nutritional 
supplements. As shared by a community health worker: "I usually ask them about the type of vitamins they take. They tell me that they sometimes even buy multivitamins."

Also, beneficiaries had become very particular on the food products they purchase. Their budget allocation was more focused on improving food consumption among children. Hence, most of them spent the health grant on more nutritious meals that include fruits, vegetables, milk, and fish.

\subsection{Improved uptake of health care services}

Compliance with the program's health conditionalities required that the beneficiaries should frequently utilize health care services. The ability of the beneficiaries to use such services was enhanced since they were prioritized in the provision of health care services. As a result, they regularly updated their record at the barangay health center on a weekly or monthly basis. One participant reported: "I visit the health center every month for the update of my health record and my child's checkup regardless whether he has sickness or none." This was confirmed by a program implementer who remarked: "Some may just be forced to visit the health center, but this is still a good thing. This is because the people more frequently use health centers than they were in the past."

Beneficiaries were then empowered to avail of free preventive health services. These services, as stipulated in the grant conditionalities, included immunization, weight monitoring, deworming, and pre- and post-natal consultation. Some of them even availed of health services offered by the municipal health center, public hospitals, and even private clinics. As one participant articulated: "This time, I no longer worry of not being admitted to any public hospital for as long as I have 4Ps beneficiary I.D."

Closely intertwined with these positive developments was the fair treatment given by health care workers to the beneficiaries. This was evidenced in the following comments:

"From the moment we became 4Ps beneficiaries, we have been receiving the same kind of treatment. We are never taken for granted."

"They check my children's health status. They know what should be done best, especially when my children are sick."

\subsection{Increased awareness of health issues}

The Family Development Session served as an effective platform for educating beneficiaries on different health issues. Based on field observation, the one-hour session is a combination of 
lecture, discussion, and group sharing. Most of the beneficiaries acknowledged that monthly attendance at FDS had provided them an additional learning experience. As one of them shared: "We are given several lessons on issues that contribute to additional knowledge. These are the things that we can teach to our children."

The topics discussed at FDS included practical lessons aimed at instilling knowledge, skills, and values to parents. Resource speakers were often tapped to facilitate the session among beneficiaries. According to an implementer, the lessons drawn from a set of module guides were based on the needs of the beneficiaries. An example he shared: "If we notice that gambling is common in a specific barangay, we will come up with a session that focuses on how beneficiaries can stay away from gambling."

One of the key issues tackled in FDS was responsible parenthood. According to the participants, they became more knowledgeable about raising and disciplining children as well as using family planning methods. They perceived FDS as an influential factor in helping them gain a better understanding of their roles as parents. As one participant commented: "I learned about the importance of taking care of my children."

\subsection{Improved living conditions}

For most of the participants, the impact of the program went beyond the improvement of their health practices. They admitted that the program significantly transformed their perspectives on and attitudes toward raising a family. They had developed a sense of initiative and responsibility that enabled them to prioritize their children's needs. As articulated by an implementer: "They the money they receive for their children."

Some beneficiaries even looked for other means to earn money. They either looked for parttime work or engaged in small-scale business. Through this, they were able to save money to meet both health and educational needs of their children. In particular, for most of the participants, the money they used for complying with the health conditions significantly contributed to improved health and nutritional status. They claimed that their children were no longer sickly. As one shared: "Before, they would instantly catch a cold. But now, I can say that they have strong and healthy bodies that are protected from diseases." An implementer confirmed this change and shared: "They learned that they need to go the health center even if their children are not sick."

The mandatory checkup thus instilled in them a sense of preparedness. This was reflected 
not only in spending on children's needs but also in constantly monitoring their health conditions. As verbalized by a beneficiary: "I do not wait for sickness to get worse. It will be more difficult for us if it gets worse."

The program also served as a life-changing instrument. A participant admitted that her husband used to be addicted to alcohol and gambling. Another beneficiary also confessed her guilt of taking pleasure in gambling. She shared that after she became a beneficiary, she "stayed away from it." Their inclusion in the program changed their perceptions of the value of money. Generally, the cash grants were believed to have let them experience a "life of comfort."

\subsection{Responsive Program Implementation}

The combined efforts of the implementers proved to help make the program more responsive to the beneficiaries' needs. This has then resulted in a high compliance rate of $95 \%$ in terms of meeting health conditionalities for the municipality. This was despite the lack of personnel involved in the implementation of the program coupled with the increasing number of beneficiaries. A contributing factor to the high turnout rate was the considerable amount of effort allotted by the implementers on the monitoring process. As one of them reported: "We go to their houses just to remind them of their responsibility to have their children's checkup."

Monitoring was done either monthly or every two months. It entailed the usage of monitoring tools which were distributed to community health workers and collected by social workers after two months. Specifically, a columnar book was used as a family profiling instrument for recording health conditions of newborn, infant, children, pregnant women, family planning users and non-users, persons with a disability, and elderly. As explained by an implementer: "This is a tool made by the DOH for a more detailed and complete monitoring to be accomplished by the community health team." Beneficiaries were also required to bring their own notebook "to record their visit." To facilitate efficiency in monitoring at the community level, each health worker is assigned an estimated 20 households. The FDS also served as a means for directly monitoring the beneficiaries, particularly parents who were its usual attendees. The municipal social workers were in charge of facilitating the session per month.

When asked how they were monitored, most of the participants stated that they were aware that social workers were keeping track of their compliance with the program's conditions. As evidenced in the following verbalizations: "We are being checked out. We are reminded of the rules, that the cash grants should only be used for meeting education and health needs." In 
particular, they were constantly told of the possible consequences they may incur once they got caught misusing their cash grants.

\subsection{Persisting implementation challenges}

The implementation of 4Ps at the community level was perceived by both beneficiaries and implementers to be confronted with problems. These problems were mostly related to the use of cash grants, compliance of beneficiaries, and limited resources. Most of the participants stated that they were able to comply with the program conditionalities. Only a few of them experienced setback due to their inability to attend FDS. As one of them shared: "There was an instance when FDS was called for, and I could not leave my work."

Another reason for non-compliance was the failure to visit the health center for the regular checkup. There was a consensus among implementers that there were parents who seemed to neglect their responsibilities as beneficiaries. As verbalized by an implementer: "It is saddening that there are those who forget to have their checkup even if it only requires them to do it once in every two months." Another one said: "They would tell us that their children are not sick. It does not mean that if the child is not sick, his health should no longer be monitored."

Although aware of their shortcomings, some beneficiaries still complained of the deductions made from their cash grants. According to one of the implementers, they did not realize that the program also enabled them to attain some ends for improved living. Hence, he remarked: "The biggest issue here is how they only view the program as a means for them to get money."

A more serious concern revolved around the misuse of cash grants. Implementers received reports on the pawning of cash cards and gambling of beneficiaries. According to the program's guide booklet, these were acts that were subject to warning, suspension from the program, or cancellation of the grant. As an early intervention to address non-compliance, community health workers performed home visits and reminded beneficiaries of their responsibilities. Furthermore, non-compliant beneficiaries underwent group counseling conducted by municipal implementers.

As they responded to the preceding problems, the implementers also had to address the challenges they faced. Two emerging problems were the limited number of personnel and lack of incentives. The increasing number of household beneficiaries raised the need for more dedicated workers. This was particularly crucial in a community that served as a relocation site for informal settlers who were already 4Ps members before their displacement. As shown in the following comments of the implementers: 
"It is a challenging task. You always have to visit them even though we do not receive any incentive."

"I sometimes think of resigning from my work. However, I also think of those beneficiaries who always depend on me."

\section{Implications}

The findings of this study provide the following implications for future practice. First, while it is evident that the 4Ps has led to positive impacts, continued efforts are needed to ensure the sustainability of the program's outcomes. The adequacy of health facilities and services should always be ensured to meet the objectives of the program implementation. This can be translated into adequate health care received by beneficiaries since they are prioritized in the delivery of free essential health services.

Second, priority should be placed on the program's transformative aspect of increasing awareness on health issues among parents. Attendance at FDS as a critical requirement for compliance proves to be a beneficial educational platform for raising such awareness. Though informal, it is found to foster positive values. This then implies the need to reinforce further the delivery of learning outcomes focused on a holistic understanding of parental roles and responsibilities. Eventually, parent attendees will become advocates of responsible parenthood within their communities. In the long run, such an additional learning experience for the beneficiaries may lead to life-long improvements.

Lastly, ensuring the support mechanism to the implementers, particularly at the community level, should be carefully addressed. This is to eliminate the risks of achieving poor performance in responding to the community's health needs and losing dedicated and committed personnel. Interventions, which may be made as part of the more substantial health sector reforms, can aim to improve their work satisfaction.

\section{Conclusion and Recommendations}

This qualitative research has surfaced the dominant themes that encompass the beneficiaries' insights on $4 \mathrm{Ps}^{\prime}$ impacts on health outcomes. Most of these insights are directly related to the positive impacts brought about by the strict compliance of beneficiaries to meet the program conditionalities.

The program not only has obliged households to follow the conditions but also has influenced 
them to undertake measures to improve their living conditions voluntarily. As a result, they have learned to prioritize their health needs as manifested by their careful selection of food products and regular visits at the health center, which they admittedly did not give too much importance in the past. They have also increased their efforts in utilizing health care services and increasing their knowledge on health issues, leading to the improvement of their living conditions.

The above-mentioned positive developments may already constitute a promising future. There are already indications of how the program has transformed the beneficiaries' lives although substantial evidence is still needed to consider $4 \mathrm{Ps}$ as a silver bullet against poverty. The program's transformative aspect is yet to be observed especially on its impacts on poverty reduction.

However, several challenges remain to be addressed. A primary concern deals with the need to increase the number of personnel who will be directly involved in monitoring the compliance of an increasing number of beneficiary households. A more serious concern revolves around the provision of incentives for community health workers who often serve as front liners in responding to the beneficiaries' needs.

The results show how the implementation of 4Ps has resulted in significant improvements in health outcomes at the community level. However, there are still courses of actions that should be taken into account to drive its sustainability. A primary consideration is ensuring the supply-side interventions are adequate to meet the program's objectives. It is also recommended that the needs of all household members, not just of the children and pregnant women, should be given emphasis. In this regard, it is essential to segment the households in terms of their poverty status, that is, whether they are living in either transient or chronic poverty. This is to guarantee that the targeted interventions are aimed at addressing the needs of every poor household at the optimum level. In evaluating then the impacts of the program, it is imperative to determine how the program has significantly reduced poverty incidence not just in the context of health and educational outcomes.

This study was delimited by its use of qualitative methods. It focused only on examining the perceived impact of 4Ps on health outcomes. This is done through the use of qualitative data obtained from only one village in a rural municipality. Such data constitute the pathways through which the impact occurs. Moreover, the findings of this study do not reflect the experiences of the majority of beneficiaries in a given community. Further investigation that obtains a larger sample can be done to generalize the findings to the population. Triangulation of quantitative and 
qualitative methods can be applied to the evaluation of the CCT program to yield a thicker and a richer set of data.

\section{REFERENCES}

Adato, M., \& Hoddinott, J. (2010). Conditional cash transfer programs: A "magic bullet"? In M. Adato \& J. Hoddinott (Eds.), Conditional cash transfers in Latin America (pp. 3-25). Baltimore, MD: The Johns Hopkins University Press.

Adato, M., Roopnaraineb, T., \& Beckera, E. (2011). Understanding use of health services in conditional cash transfer programs: Insights from qualitative research in Latin America and Turkey. Social Science \& Medicine, 72, 1921-1929. doi:10.1016/j.socscimed.2010.09.032

Attride-Stirling, J. (2001). Thematic networks: An analytic tool for qualitative research. Qualitative Research, 1(3), 385-405.

Department of Social Welfare and Development. (2014). Keeping children healthy and in school: Evaluating the Pantawid Pamilya Using Regression Discontinuity Design (Second Wave $\begin{array}{llll}\text { Impact Evaluation } & \text { Results). } & \text { Retrieved }\end{array}$ http://www.dswd.gov.ph/download/pantawid_pamilya_impact_evaluation/Pantawid\%20Pam ilya\%20Impact\%20Evaluation\%202014\%20Report\%20Final.pdf

Fernandez, L., \& Olfindo, R. (2011). Overview of the Philippines' conditional cash transfer program: The Pantawid Pamilyang Pilipino Program (Pantawid Pamilya) (Philippine Social Protection Note No. 2). Retrieved from The World Bank website: http://siteresources.worldbank.org/INTPENSIONS/Resources/3954431142535808399/2329423-1350588199143/8898265-1350588563122/philippines_cct.pdf

Fiszbein, A., \& Schady, N. (2009) Conditional Cash Transfers: Reducing Present and Future Poverty. Washington, DC: The International Bank for Reconstruction and Development / The World Bank

Glassman, A., Duran, D., Fleisher, L., Singer, D., Sturke, R., Angeles, G.,. . . Koblinsky, M. (2013). Impact of conditional cash transfers on maternal and newborn health. Journal of Health, Nutrition and Nutrition, 31(4), S48-S66.

Maluccio, J.A., Adato, M., \& Skoufias, E. (2010). Combining quantitative and qualitative research methods for evaluation of conditional cash transfer programs in Latin America. In M. Adato \& J. Hoddinott (Eds.), Conditional cash transfers in Latin America (pp. 26-52). Baltimore, MD: The Johns Hopkins University Press. 
Manasan, R.G. (2011). Pantawid Pamilyang Pilipino Program and school attendance: early indications of success (Policy Notes No. 2011-19). Retrieved from Philippine Institute for Development Studies website: http://dirp4.pids.gov.ph/ris/pn/pidspn1119.pdf

National Economic and Development Council. (2014). The Philippines: Fifth Progress Report Millennium Development Goals. Retrieved from http://www.neda.gov.ph/wpcontent/uploads/2014/08/MDG-Progress-Report-5-Final.pdf

Owusu-Addo, E. (2014). Perceived impact of Ghana's conditional cash transfer on child health. Health Promotion International, 1-11. doi:10.1093/heapro/dau069

Philippine Statistics Authority. (2013). Philippines National Demographic and Health Survey 2013. Manila / Rockville, MD: Author and ICF International.

Reyes, C.M., \& Tabuga, A.D. (2012). Conditional cash transfer program in the Philippines: Is it reaching the extremely poor? (Discussion Paper Series No. 2012-42). Retrieved from Philippine Institute for Development Studies website: http://dirp4.pids.gov.ph/ris/dps/pidsdps1242.pdf

Save the Children Federation. (2015). The urban disadvantage: State of the World's Mothers 2015. Fairfield, C.T.: Author.

Skovdal, M., Mushati, P., Robertson, L. Munyati, S., Sherr, L., Nyamukapa, C., \& Gregson, S. (2013). Social acceptability and perceived impact of a community-led cash transfer programme in Zimbabwe. BMC Public Health, 13(342), 1-13.

Yildirima, J., Ozdemirb, S., \& Sezginb, F. (2014). A qualitative evaluation of a conditional cash transfer program in Turkey: The beneficiaries' and key informants' perspectives. Journal of Social Service Research, 40(1), 62-79. doi: $10.1080 / 01488376.2013 .845127$ 
How to cite this article:

APA:

Peñalba, E. H. (2019, July). Exploring the Health Outcomes of a Conditional Cash Transfer Program in Rural Philippines. Journal of Social Work Education and Practice, IV(3), 37-51.

MLA:

Peñalba, Ericson H. "Exploring the Health Outcomes of a Conditional Cash Transfer Program in Rural Philippines." Journal of Social Work Education and Practice IV.3 (2019): 37-51.

Chicago:

Peñalba, Ericson H. 2019. "Exploring the Health Outcomes of a Conditional Cash Transfer Program in Rural Philippines." Journal of Social Work Education and Practice IV (3): 37-51. 